\title{
Erratum
}

\section{UK Prevalence of Chronic Kidney Disease for the Adult Population Is 6.76\% Based on Two Creatinine Readings}

\author{
Simon de Lusignan ${ }^{a} \quad$ Charles Tomson $^{b} \quad$ Kevin Harris $^{c} \quad$ Jeremy van Vlymen ${ }^{a} \quad$ Hugh Gallagher $^{d}$ \\ ${ }^{a}$ Division of Community Health Sciences, St. George's, University of London, London, ' Department of Renal Medicine, \\ Southmead Hospital, Bristol, ' John Walls Renal Unit, Leicester General Hospital, University Hospitals of Leicester, Leicester, \\ and ${ }^{\mathrm{I}}$ SW Thames Renal Unit, St. Helier Hospital, Carshalton, UK
}

We would like to correct an error in our paper about the UK prevalence of chronic kidney disease (CKD) [1]. We incorrectly made comparisons of the prevalence of CKD with other studies based on the denominator being the whole population rather than just adults.

Although our central thesis that 'relying on a single eGFR reading with no allowance for fluctuation has a greater influence on prevalence than using CKD-EPI instead of MDRD' still applies, we incorrectly compared population prevalence with the prevalence in adults. When we just include adults as the denominator in our estimations of prevalence we inevitably get a higher prevalence, which is much more similar to other studies, notably NEOERICA [2].

The prevalence of CKD in the Quality Improvement in Chronic Kidney Disease (QICKD) trial [3] using two estimates of glomerular filtration rate (eGFR) in the adult population is $6.76 \%$ compared with the $5.4 \%$ for the whole population we quoted in our paper. However, if we just use the single latest eGFR reading, the

Table 1. The prevalence of CKD for the adult population in the QICKD trial baseline data

\begin{tabular}{lccc}
\hline MDRD & Female & Male & $\begin{array}{c}\text { Popu- } \\
\text { lation }\end{array}$ \\
\hline Stage 3-5 CKD & 34,106 & 16,213 & 50,319 \\
Population >18 & 374,567 & 369,649 & 744,216 \\
\hline Prevalence taking into account chronicity & 9.11 & 4.39 & 6.76 \\
\hline Latest eGFR stage 3-5 CKD & 39,808 & 19,839 & \multicolumn{1}{c}{59,647} \\
Population >18 & 374,567 & 369,649 & 744,216 \\
\hline Prevalence based on latest eGFR & 10.63 & 5.37 & 8.01 \\
\hline NEOERICA prevalence & $10.60 \%$ & $5.80 \%$ & $8.50 \%$ \\
\hline
\end{tabular}

MDRD $=$ Modified Diet in Renal Disease

prevalence rises to $8.0 \%$ (table 1) compared with the quoted $6.7 \%$ in the population as a whole. The adult QICKD trial prevalence when using a single creatinine reading, at $8.0 \%$, is very close to the prevalence reported in the NEOERICA study and not different as we suggest in the discussion section of our paper. The preva- lence for females is very similar, and the difference in male prevalence is $0.43 \%$. This reinforces the importance of allowing for chronicity when estimating the prevalence of CKD but displays a similarity rather than a difference between prevalence estimates made on routinely collected UK primary care data.

\section{References}

1 de Lusignan S, Tomson C, Harris K, van Vlymen J, Gallagher H: Creatinine fluctuation has a greater effect than the formula to estimate glomerular filtration rate on the prevalence of chronic kidney disease. Nephron Clin Pract 2011;117:c213-c224.

-2 Stevens PE, O’Donoghue DJ, de Lusignan S, Van Vlymen J, Klebe B, Middleton R, Hague N, New J, Farmer CK: Chronic kidney disease management in the United Kingdom: NEOERICA project results. Kidney Int 2007; 72:92-99.
3 de Lusignan S, Gallagher H, Chan T, Thomas $\mathrm{N}$, van Vlymen J, Nation M, Jain N, Tahir A, du Bois E, Crinson I, Hague N, Reid F, Harris $\mathrm{K}$ : The QICKD study protocol: a cluster randomised trial to compare quality improvement interventions to lower systolic BP in chronic kidney disease (CKD) in primary care. Implement Sci 2009;4:39.

\section{KARGER}

Fax +4161306 1234 E-Mail karger@karger.ch www.karger.com
Simon de Lusignan, Professor of Primary Care and Clinical Informatics Department of Health Care Management and Policy University of Surrey Guildford, GU2 7XH (UK)

Tel. +44 1483683 089, E-Mail s.lusignan@surrey.ac.uk 